\title{
Composition of Cesàro and backward difference operators
}

Hadi Roopaei ${ }^{1 *}$ and Bipan Hazarika²

Dedicated to Prof. Maryam Mirzakhani who, in spite of a short lifetime, made a long standing impact on mathematics

"Correspondence:

h.roopaei@gmail.com;

bh_rgu@yahoo.co.in

${ }^{1}$ Department of Mathematics,

University of Alberta, Edmonton,

Canada

Full list of author information is

available at the end of the article

\begin{abstract}
In this research, we combine the Cesàro and backward difference operators of different orders which results in introducing a matrix who has two different behaviors and includes several matrices. We also investigate the Köthe duals and inclusion relations of the associated sequence space of this new matrix. Moreover, we compute the norm of this matrix on some well-known sequence spaces.
\end{abstract}

MSC: 26D15; 40C05; 40G05; 47B37

Keywords: Cesàro matrix; Backward difference matrix; Norm; Sequence space

\section{Introduction}

Let $\omega$ be the space of all real-valued sequences. The space $\ell_{p}$ consists all real sequences $u=\left(u_{k}\right)_{k=0}^{\infty} \in \omega$ such that $\sum_{k=0}^{\infty}\left|u_{k}\right|^{p}<\infty$, which is a Banach space with the norm

$$
\|u\|_{\ell_{p}}=\left(\sum_{k=0}^{\infty}\left|u_{k}\right|^{p}\right)^{1 / p}<\infty,
$$

where $1<p<\infty$.

The matrix domain of an infinite matrix $T$ in a sequence space $X$ is defined as

$$
X_{T}=\{x \in \omega: T x \in X\}
$$

which is also a sequence space. By using matrix domains of special triangle matrices in classical spaces, many authors have introduced and studied new Banach spaces. For the relevant literature, we refer to the papers [1-16] and the textbooks [17] and [18].

The Köthe dual $(\alpha-, \beta-, \gamma$-duals) of a sequence space $X$ are defined by

$$
\begin{aligned}
& X^{\alpha}=\left\{a=\left(a_{k}\right) \in \omega: \sum_{k=1}^{\infty}\left|a_{k} x_{k}\right|<\infty \text { for all } x=\left(x_{k}\right) \in X\right\}, \\
& X^{\beta}=\left\{a=\left(a_{k}\right) \in \omega:\left(\sum_{k=1}^{n} a_{k} x_{k}\right) \in c \text { for all } x=\left(x_{k}\right) \in X\right\},
\end{aligned}
$$

(c) The Author(s) 2021. This article is licensed under a Creative Commons Attribution 4.0 International License, which permits use, sharing, adaptation, distribution and reproduction in any medium or format, as long as you give appropriate credit to the original author(s) and the source, provide a link to the Creative Commons licence, and indicate if changes were made. The images or other third party material in this article are included in the article's Creative Commons licence, unless indicated otherwise in a credit line to the material. If material is not included in the article's Creative Commons licence and your intended use is not permitted by statutory regulation or exceeds the permitted use, you will need to obtain permission directly from the copyright holder. To view a copy of this licence, visit http://creativecommons.org/licenses/by/4.0/. 


$$
X^{\gamma}=\left\{a=\left(a_{k}\right) \in \omega:\left(\sum_{k=1}^{n} a_{k} x_{k}\right) \in \ell_{\infty} \text { for all } x=\left(x_{k}\right) \in X\right\},
$$

respectively.

Consider the Hausdorff matrix $H^{\mu}=\left(h_{j k}\right)_{j, k=0}^{\infty}$, with entries of the form

$$
h_{j k}= \begin{cases}\left(\begin{array}{l}
j \\
k
\end{array}\right) \int_{0}^{1} \theta^{k}(1-\theta)^{j-k} d \mu(\theta), & 0 \leq k \leq j, \\
0, & k>j,\end{cases}
$$

where $\mu$ is a probability measure on $[0,1]$. The Hausdorff matrix contains some famous classes of matrices. For positive integer $n$, by choosing $d \mu(\theta)=n(1-\theta)^{n-1} d \theta$ the Cesàro matrix $C^{n}=\left(c_{j k}^{n}\right)$ of order $n$ is defined as follows:

$$
c_{j k}^{n}= \begin{cases}\frac{\left(\begin{array}{c}
n+j-k-1 \\
j-k
\end{array}\right)}{\left(\begin{array}{c}
n+j \\
j
\end{array}\right)}, & 0 \leq k \leq j, \\
0, & \text { otherwise. }\end{cases}
$$

Hardy's formula ([19], Theorem 216) states that the Hausdorff matrix is a bounded operator on $\ell_{p}$ if and only if $\int_{0}^{1} \theta^{\frac{-1}{p}} d \mu(\theta)<\infty$ and

$$
\left\|H^{\mu}\right\|_{\ell_{p}}=\int_{0}^{1} \theta^{\frac{-1}{p}} d \mu(\theta)
$$

hence the Cesàro matrix has the norm

$$
\left\|C^{n}\right\|_{\ell_{p}}=\frac{\Gamma(n+1) \Gamma\left(1 / p^{*}\right)}{\Gamma\left(n+1 / p^{*}\right)}
$$

where $p^{*}$ is the conjugate of $p$ i.e. $\frac{1}{p}+\frac{1}{p^{*}}=1$. Note that $C^{1}$ is the well-known Cesàro matrix $C$ with $\|C\|_{\ell_{p}}=p^{*}$. The author has introduced the sequence spaces $C_{p}^{n}$ and $C_{\infty}^{n}$ as the set of all sequences whose $C^{n}$-transforms are in the spaces $\ell_{p}$ and $\ell_{\infty}$, respectively; that is,

$$
C_{p}^{n}=\left\{x=\left(x_{j}\right) \in \omega: \sum_{j=0}^{\infty}\left|\frac{1}{\left(\begin{array}{c}
n+j \\
j
\end{array}\right)} \sum_{k=0}^{j}\left(\begin{array}{c}
n+j-k-1 \\
j-k
\end{array}\right) x_{k}\right|^{p}<\infty\right\}
$$

and

$$
C_{\infty}^{n}=\left\{x=\left(x_{j}\right) \in \omega: \sup _{j}\left|\frac{1}{\left(\begin{array}{c}
n+j \\
j
\end{array}\right)} \sum_{k=0}^{j}\left(\begin{array}{c}
n+j-k-1 \\
j-k
\end{array}\right) x_{k}\right|<\infty\right\} .
$$

Backward difference matrix. The backward difference matrix of order $n, \Delta^{n}=\left(\delta_{j k}^{n}\right)$, is defined by

$$
\delta_{j k}^{n}= \begin{cases}(-1)^{j-k}\left(\begin{array}{c}
n \\
j-k
\end{array}\right), & k \leq j \leq k+n, \\
0, & \text { otherwise. }\end{cases}
$$


This matrix has the inverse $\Delta^{-n}=\left(\delta_{j k}^{-n}\right)$ which has the following entries:

$$
\delta_{j k}^{-n}= \begin{cases}\left(\begin{array}{c}
n+j-k-1 \\
j-k
\end{array}\right), & j \geq k \geq 0 \\
0, & \text { otherwise }\end{cases}
$$

Motivation. The inverse of the backward difference matrix has some similarities in the definition to the Cesàro matrix, hence composing of the Cesàro matrix and the backward difference matrix results in two different cases: one acts like the backward and the other acts like the inverse of the backward difference operator. In this study, we try to discover some results of these combinations covering both types of operators. Therefore, the present study is a generalization of much research.

\section{Composition of the Cesàro and backward difference matrices}

Suppose that $n, m$ are two non-negative integers and $1<p<\infty$. Let us define the matrix $S^{n, m}=\left(s_{j k}^{n, m}\right)$ by

$$
S^{n, m}=C^{n} \Delta^{m}
$$

where $C^{n}$ and $\Delta^{m}$ are the Cesàro and backward difference matrices of order $n$ and $m$, defined by Eqs. (1.1) and (1.6), respectively.

Note that $S^{1,0}=C, S^{n, 0}=C^{n}, S^{0,1}=\Delta$ and $S^{0, m}=\Delta^{m}$. The sequence space associated with this matrix, $\ell_{p}\left(S^{n, m}\right)$, includes the following spaces:

$$
\begin{aligned}
& \ell_{p}\left(S^{1,0}\right):=C_{p}, \\
& \ell_{p}\left(S^{n, 0}\right):=C_{p}^{n}, \\
& \ell_{p}\left(S^{0,1}\right):=b v_{p}, \\
& \ell_{p}\left(S^{0, m}\right):=\ell_{p}\left(\Delta^{m}\right), \\
& \ell_{p}\left(S^{1, m}\right):=C_{p}\left(\Delta^{m}\right) ;
\end{aligned}
$$

these have been investigated in [7, 20-26], respectively.

With regard to the cases $n \geq m$ or $n \leq m$ we encounter two different types of matrix $S^{n, m}$, which we define by $\Phi^{n, m}$ and $\Psi^{n, m}$, respectively. They are

$$
S^{n, m}:=\Phi^{n, m}, \quad n \geq m \geq 0,
$$

and

$$
S^{n, m}:=\Psi^{n, m}, \quad 0 \leq n \leq m
$$

We can represent the matrices $\Phi^{n, m}=\left(\phi_{j k}^{n, m}\right)$ and $\Psi^{n, m}=\left(\psi_{j k}^{n, m}\right)$ by their entries as follows:

$$
\phi_{j k}^{n, m}= \begin{cases}\frac{\left(\begin{array}{c}
n-m+j-k-1 \\
j-k
\end{array}\right)}{\left(\begin{array}{c}
n+j \\
j
\end{array}\right)}, & 0 \leq k \leq j, \\
0, & \text { otherwise }\end{cases}
$$

and

$$
\psi_{j k}^{n, m}= \begin{cases}\frac{(-1)^{j-k}\left(\begin{array}{c}
m-n \\
j-k
\end{array}\right)}{\left(\begin{array}{c}
n+j \\
j
\end{array}\right)}, & 0 \leq k \leq j, \\
0, & \text { otherwise. }\end{cases}
$$


Lemma 2.1 The matrices $\Phi^{n, m}$ and $\Psi^{n, m}$ are invertible and their inverse $\left(\Phi^{n, m}\right)^{-1}=$ $\left(\left(\phi^{n, m}\right)_{j k}^{-1}\right)$ and $\left(\Psi^{n, m}\right)^{-1}=\left(\left(\psi^{n, m}\right)_{j k}^{-1}\right)$ are defined by

$$
\left(\phi^{n, m}\right)_{j k}^{-1}= \begin{cases}(-1)^{j-k}\left(\begin{array}{c}
n-m \\
j-k
\end{array}\right)\left(\begin{array}{c}
n+k \\
k
\end{array}\right), & k \leq j \leq n-m+k \\
0, & \text { otherwise }\end{cases}
$$

and

$$
\left(\psi^{n, m}\right)_{j k}^{-1}= \begin{cases}\left(\begin{array}{c}
m-n+j-k-1 \\
j-k
\end{array}\right)\left(\begin{array}{c}
n+k \\
k
\end{array}\right), & j \geq k \geq 0 \\
0, & \text { otherwise. }\end{cases}
$$

Proof Since $S^{n, m}=C^{n} \Delta^{m}$ we have $\left(S^{n, m}\right)^{-1}=\Delta^{-m} C^{-n}$ or

$$
\left(S^{n, m}\right)_{j k}^{-1}=\sum_{i} \delta_{j i}^{-m} \delta_{i k}^{n}\left(\begin{array}{c}
n+k \\
k
\end{array}\right)=\delta_{j k}^{n-m}\left(\begin{array}{c}
n+k \\
k
\end{array}\right) .
$$

Now, by the definition of the backward difference operator, Eqs. (1.6) and (1.7)

$$
\left(\phi^{n, m}\right)_{j k}^{-1}=(-1)^{j-k}\left(\begin{array}{c}
n-m \\
j-k
\end{array}\right)\left(\begin{array}{c}
n+k \\
k
\end{array}\right)
$$

and

$$
\left(\psi^{n, m}\right)_{j k}^{-1}=\left(\begin{array}{c}
m-n+j-k-1 \\
j-k
\end{array}\right)\left(\begin{array}{c}
n+k \\
k
\end{array}\right)
$$

Theorem 2.2 Let $n$ and $m$ be two non-negative integers and $x \in \ell_{p}$. We have the following inequalities:

$$
\left\|S^{n, m} x\right\|_{\ell_{p}} \leq \frac{\Gamma(n+1) \Gamma\left(1 / p^{*}\right)}{\Gamma\left(n+1 / p^{*}\right)}\left\|\Delta^{m} x\right\|_{\ell_{p}} .
$$

In particular, we have the following.

For $m=0$

$$
\left\|C^{n} x\right\|_{\ell_{p}} \leq \frac{\Gamma(n+1) \Gamma\left(1 / p^{*}\right)}{\Gamma\left(n+1 / p^{*}\right)}\|x\|_{\ell_{p}} .
$$

For $n=1$ and $m=0$ we have Hardy's inequality,

$$
\|C x\|_{\ell_{p}} \leq \frac{p}{p-1}\|x\|_{\ell_{p}}
$$

Proof By the definition of the matrix $S^{n, m}$ we have

$$
\left\|S^{n, m} x\right\|_{\ell_{p}}=\left\|C^{n} \Delta^{m} x\right\|_{\ell_{p}} \leq\left\|C^{n}\right\|_{\ell_{p}}\left\|\Delta^{m} x\right\|_{\ell_{p}}=\frac{\Gamma(n+1) \Gamma\left(1 / p^{*}\right)}{\Gamma\left(n+1 / p^{*}\right)}\left\|\Delta^{m} x\right\|_{\ell_{p}} .
$$

The following inclusions are the straightforward results of the above theorem. 
Corollary 2.3 Let $n$ and $m$ are two non-negative integers and $x \in \ell_{p}$. Then

$$
\ell_{p}\left(\Delta^{m}\right) \subset \ell_{p}\left(S^{n, m}\right)
$$

In particular,

$$
\begin{aligned}
& \ell_{p}\left(\Delta^{m}\right) \subset C_{p}\left(\Delta^{m}\right), \\
& \ell_{p} \subset C_{p}^{n} .
\end{aligned}
$$

Theorem 2.4 The spaces $\ell_{p}\left(S^{n, m}\right)$ and $\ell_{\infty}\left(S^{n, m}\right)$ are linearly isomorphic to $\ell_{p}$ and $\ell_{\infty}$, respectively. In particular, we have the following.

The spaces $C_{p}^{n}$ and $C_{\infty}^{n}$ are linearly isomorphic to $\ell_{p}$ and $\ell_{\infty}$, respectively ([7],

Theorem 2.4).

The spaces $\ell_{p}\left(\Delta^{n}\right)$ and $\ell_{\infty}\left(\Delta^{n}\right)$ are linearly isomorphic to $\ell_{p}$ and $\ell_{\infty}$, respectively.

Proof Let us define the map $T: \ell_{p}\left(S^{n, m}\right) \rightarrow \ell_{p}$ with $T(u)=S^{n, m} u$ for any $u \in \ell_{p}\left(S^{n, m}\right)$. It is clear that $T$ is linear and one-to-one. Also, since $S^{n, m}$ is invertible, $T$ is onto. Now, since $\|u\|_{\ell_{p}\left(S^{n, m}\right)}=\left\|S^{n, m} u\right\|_{\ell_{p}}$ holds, we find that $T$ preserves the norms. This completes the proof.

Theorem 2.5 The inclusion $\ell_{p}\left(S^{n, m}\right) \subset \ell_{q}\left(S^{n, m}\right)$ strictly holds, where $1<p<q<\infty$. In particular, we have the following.

The inclusion $C_{p}^{n} \subset C_{q}^{n}$ strictly holds.

The inclusion $\ell_{p}\left(\Delta^{n}\right) \subset \ell_{q}\left(\Delta^{n}\right)$ strictly holds.

Proof Let $u \in \ell_{p}\left(S^{n, m}\right)$. Then we have $S^{n, m} u \in \ell_{p}$. Since the inclusion $\ell_{p} \subset \ell_{q}$ holds for $1<p<q<\infty$, we have $S^{n, m} u \in \ell_{q}$. This implies that $u \in \ell_{q}\left(S^{n, m}\right)$. Hence, we conclude that the inclusion $\ell_{p}\left(S^{n, m}\right) \subset \ell_{q}\left(S^{n, m}\right)$ holds.

Now, we show that the inclusion is strict. Since the inclusion $\ell_{p} \subset \ell_{q}$ is strict, we can choose $v \in \ell_{q} \backslash \ell_{p}$. Define the sequence $u=\left(S^{n, m}\right)^{-1} v$, which means $S^{n, m} u=v$ and so $S^{n, m} u \in \ell_{q} \backslash \ell_{p}$. Hence, we conclude that $u \in \ell_{q}\left(S^{n, m}\right) \backslash \ell_{p}\left(S^{n, m}\right)$ and so the inclusion $\ell_{p}\left(S^{n, m}\right) \subset \ell_{q}\left(S^{n, m}\right)$ is strict.

Theorem 2.6 The inclusion $\ell_{p}\left(S^{n, m}\right) \subset \ell_{\infty}\left(S^{n, m}\right)$ strictly holds. In particular, we have the following.

The inclusion $C_{p}^{n} \subset C_{\infty}^{n}$ strictly holds.

The inclusion $\ell_{p}\left(\Delta^{n}\right) \subset \ell_{\infty}\left(\Delta^{n}\right)$ strictly holds.

Proof Let $u \in \ell_{p}\left(S^{n, m}\right)$. Then we have $S^{n, m} u \in \ell_{p}$. Since the inclusion $\ell_{p} \subset \ell_{\infty}$ holds for $1<p<\infty$, we have $S^{n, m} u \in \ell_{\infty}$. This implies that $u \in \ell_{\infty}\left(S^{n, m}\right)$. Hence, we conclude that the inclusion $\ell_{p}\left(S^{n, m}\right) \subset \ell_{\infty}\left(S^{n, m}\right)$ holds.

Now, we show that the inclusion is strict. Consider the sequence $v=\left(v_{j}\right)=(-1)^{j}$ and let $u=\left(S^{n, m}\right)^{-1} v$. We deduce that $S^{n, m} u=\left((-1)^{j}\right) \in \ell_{\infty} \backslash \ell_{p}$, we obtain $u \in \ell_{\infty}\left(S^{n, m}\right) \backslash \ell_{p}\left(S^{n, m}\right)$. Consequently, the inclusion $\ell_{p}\left(S^{n, m}\right) \subset \ell_{\infty}\left(S^{n, m}\right)$ is strict.

Lemma 2.7 (Theorem 20.3, [27]) Let $1<p<\infty$ and $\alpha>\beta \geq 0$. The Cesàro matrix of order $\alpha, C^{\alpha}$, has a factorization of the form

$$
C^{\alpha}=\mathcal{R}^{\alpha, \beta} C^{\beta}=C^{\beta} \mathcal{R}^{\alpha, \beta},
$$


where $\mathcal{R}^{\alpha, \beta}$ is a bounded operator on $\ell_{p}$ and

$$
\left\|\mathcal{R}^{\alpha, \beta}\right\|_{\ell_{p}}=\frac{\Gamma(\alpha+1) \Gamma\left(\beta+1 / p^{*}\right)}{\Gamma(\beta+1) \Gamma\left(\alpha+1 / p^{*}\right)} .
$$

Corollary 2.8 For $\alpha>\beta \geq 0$, the inclusion $\ell_{p}\left(S^{\beta, m}\right) \subset \ell_{\infty}\left(S^{\alpha, m}\right)$ holds. In particular, for $m=0$, we have $C_{p}^{\beta} \subset C_{p}^{\alpha}$.

Proof By multiplying both sides of Eq. (2.5) in terms of $\Delta^{m}$ we obtain the equality

$$
S^{\alpha, m}=\mathcal{R}^{\alpha, \beta} S^{\beta, m} .
$$

Now, let $x \in \ell_{p}\left(S^{\beta, m}\right)$. Since

$$
\left\|S^{\alpha, m} x\right\|_{\ell_{p}} \leq\left\|\mathcal{R}^{\alpha, \beta}\right\|_{\ell_{p}}\left\|S^{\beta, m} x\right\|_{\ell_{p}}
$$

hence $x \in \ell_{p}\left(S^{\alpha, m}\right)$, which results in the inclusion.

Corollary 2.9 Let $\alpha$ and $\beta$ be two non-negative integers that $\alpha \geq \beta$. The backward difference matrix, $\Delta^{\alpha-\beta}$, is a bounded operator from $\ell_{p}$ into $\ell_{p}\left(S^{\alpha, \beta}\right)$ and

$$
\left\|\Delta^{\alpha-\beta}\right\|_{\ell_{p}, \ell_{p}(S \alpha, \beta)}=1
$$

In particular, the backward difference matrix of order $\alpha, \Delta^{\alpha}$, is a bounded operator from $\ell_{p}$ into $C_{p}^{\alpha}$ and

$$
\left\|\Delta^{\alpha}\right\|_{\ell_{p}, C_{p}^{\alpha}}=1
$$

Proof According to the definition of matrix $S^{\alpha, \beta}$ it is not difficult to prove that $S^{\alpha, \alpha}=D^{\alpha}$, where $D^{\alpha}=\left(d_{j k}^{\alpha}\right)$ is a diagonal matrix defined by

$$
d_{j k}^{\alpha}= \begin{cases}\frac{1}{\left(\begin{array}{c}
\alpha+j \\
j
\end{array}\right)}, & k=j, \\
0, & \text { otherwise. }\end{cases}
$$

Now, we have

$$
\begin{aligned}
\left\|\Delta^{\alpha-\beta}\right\|_{\ell_{p}, \ell_{p}\left(S^{\alpha, \beta}\right)} & =\sup _{x \in \ell_{p}} \frac{\left\|\Delta^{\alpha-\beta} x\right\|_{\ell_{p}\left(S^{\alpha, \beta}\right)}}{\|x\|_{\ell_{p}}}=\sup _{x \in \ell_{p}} \frac{\left\|S^{\alpha, \beta} \Delta^{\alpha-\beta} x\right\|_{\ell_{p}}}{\|x\|_{\ell_{p}}} \\
& =\left\|S^{\alpha, \alpha}\right\|_{\ell_{p}}=\sup _{j} d_{j j}^{\alpha}=1 .
\end{aligned}
$$

In particular, by letting $\beta=0, S^{\alpha, \beta}=C^{\alpha}$, we have the desired result.

Corollary 2.10 Let $\alpha$ and $\beta$ be two non-negative integers such that $\alpha>\beta \geq 0$ and $t+k=r$. The backward difference matrix, $\Delta^{k}$, is a bounded operator from $\ell_{p}\left(S^{\beta, r}\right)$ into $\ell_{p}\left(S^{\alpha, t}\right)$ and

$$
\left\|\Delta^{k}\right\|_{\ell_{p}\left(S^{\beta, r}\right), \ell_{p}\left(S^{\alpha, t}\right)}=\frac{\Gamma(\alpha+1) \Gamma\left(\beta+1 / p^{*}\right)}{\Gamma(\beta+1) \Gamma\left(\alpha+1 / p^{*}\right)} .
$$


In particular, the identity matrix, $I$, is a bounded operator from $C_{p}^{\beta}$ into $C_{p}^{\alpha}$ and

$$
\|I\|_{C_{p}^{\beta}, C_{p}^{\alpha}}=\frac{\Gamma(\alpha+1) \Gamma\left(\beta+1 / p^{*}\right)}{\Gamma(\beta+1) \Gamma\left(\alpha+1 / p^{*}\right)} .
$$

Proof According to Theorem 2.4, $\ell_{p}\left(S^{\beta, r}\right)$ and $\ell_{p}$ are isomorphic spaces. Hence by applying Lemma 2.7 we deduce that

$$
\begin{aligned}
\left\|\Delta^{k}\right\|_{\ell_{p}\left(S^{\beta, r}\right), \ell_{p}\left(S^{\alpha, t}\right)} & =\sup _{x \in \ell_{p}\left(S^{\beta, r}\right)} \frac{\left\|\Delta^{k} x\right\|_{\ell_{p}\left(S^{\alpha, t}\right)}}{\|x\|_{\ell_{p}\left(S^{\beta, r}\right)}}=\sup _{x \in \ell_{p}\left(S^{\beta, r}\right)} \frac{\left\|S^{\alpha, t} \Delta^{k} x\right\|_{\ell_{p}}}{\left\|S^{\beta, r} x\right\|_{\ell_{p}}} \\
& =\sup _{S^{\beta, r} x \in \ell_{p}} \frac{\left\|\mathcal{R}^{\alpha, \beta} S^{\beta, r} x\right\|_{\ell_{p}}}{\left\|S^{\beta, r} x\right\|_{\ell_{p}}}=\sup _{y \in \ell_{p}} \frac{\left\|\mathcal{R}^{\alpha, \beta} y\right\|_{\ell_{p}}}{\|y\|_{\ell_{p}}} \\
& =\left\|\mathcal{R}^{\alpha, \beta}\right\|_{\ell_{p}}=\frac{\Gamma(\alpha+1) \Gamma\left(\beta+1 / p^{*}\right)}{\Gamma(\beta+1) \Gamma\left(\alpha+1 / p^{*}\right)}
\end{aligned}
$$

Now, by letting $k=r=t=0$ we find the desired result.

\section{Two special cases}

The sequence spaces $\ell_{p}\left(S^{n, m}\right)$ and $\ell_{\infty}\left(S^{n, m}\right)$ are introduced as the set of all sequences whose $S^{n, m}$-transforms are in the spaces $\ell_{p}$ and $\ell_{\infty}$, respectively; that is,

$$
\ell_{p}\left(S^{n, m}\right)=\left\{u=\left(u_{j}\right) \in \omega: \sum_{j=0}^{\infty}\left|\sum_{k=0}^{j} s_{j k}^{n, m} u_{k}\right|^{p}<\infty\right\}
$$

and

$$
\ell_{\infty}\left(S^{n, m}\right)=\left\{u=\left(u_{j}\right) \in \omega: \sup _{j}\left|\sum_{k=0}^{j} s_{j k}^{n, m} u_{k}\right|<\infty\right\} .
$$

Now, regarding the double reaction of the matrix $S^{n, m}$ there are two separate sequence spaces $\ell_{p}\left(\Phi^{n, m}\right)$ and $\ell_{p}\left(\Psi^{n, m}\right)$ that have different bases and Köthe duals. In this section, we intend to investigate both these spaces.

\subsection{Fractional Cesàro spaces}

By assuming $n \geq m$ the matrix $S^{n, m}=\Phi^{n, m}$ and the associated sequence spaces $\ell_{p}\left(\Phi^{n, m}\right)$ and $\ell_{\infty}\left(\Phi^{n, m}\right)$ are introduced routinely as the set of all sequences whose $\Phi^{n, m}$-transforms are in the spaces $\ell_{p}$ and $\ell_{\infty}$, respectively; that is,

$$
\ell_{p}\left(\Phi^{n, m}\right)=\left\{u=\left(u_{j}\right) \in \omega: \sum_{j=0}^{\infty}\left|\frac{1}{\left(\begin{array}{c}
n+j \\
j
\end{array}\right)} \sum_{k=0}^{j}\left(\begin{array}{c}
n-m+j-k-1 \\
j-k
\end{array}\right) u_{k}\right|^{p}<\infty\right\}
$$

and

$$
\ell_{\infty}\left(\Phi^{n, m}\right)=\left\{u=\left(u_{j}\right) \in \omega: \sup _{j}\left|\frac{1}{\left(\begin{array}{c}
n+j \\
j
\end{array}\right)} \sum_{k=0}^{j}\left(\begin{array}{c}
n-m+j-k-1 \\
j-k
\end{array}\right) u_{k}\right|<\infty\right\} .
$$


Theorem 3.1 The spaces $\ell_{p}\left(\Phi^{n, m}\right)$ and $\ell_{\infty}\left(\Phi^{n, m}\right)$ are Banach spaces with the norms

$$
\|u\|_{\ell_{p}\left(\Phi^{n, m}\right)}=\left(\sum_{j=0}^{\infty}\left|\frac{1}{\left(\begin{array}{c}
n+j \\
j
\end{array}\right)} \sum_{k=0}^{j}\left(\begin{array}{c}
n-m+j-k-1 \\
j-k
\end{array}\right) u_{k}\right|^{p}\right)^{1 / p}
$$

and

$$
\|u\|_{\ell_{\infty}\left(\Phi^{n, m}\right)}=\sup _{j}\left|\frac{1}{\left(\begin{array}{c}
n+j \\
j
\end{array}\right)} \sum_{k=0}^{j}\left(\begin{array}{c}
n-m+j-k-1 \\
j-k
\end{array}\right) u_{k}\right|,
$$

respectively.

Proof We omit the proof which is a routine verification.

Remark 3.2 By choosing $m=0$ in the above theorem, we obtain the Cesàro sequence spaces $\ell_{p}\left(C^{n}\right)=C_{p}^{n}$ and $\ell_{\infty}\left(C^{n}\right)=C_{\infty}^{n}$, defined in [7], which are Banach spaces endowed with the norms

$$
\|u\|_{C_{p}^{n}}=\left(\sum_{j=0}^{\infty}\left|\frac{1}{\left(\begin{array}{c}
n+j \\
j
\end{array}\right)} \sum_{k=0}^{j}\left(\begin{array}{c}
n+j-k-1 \\
j-k
\end{array}\right) u_{k}\right|^{p}\right)^{1 / p}
$$

and

$$
\|u\|_{C_{\infty}^{n}}=\sup _{j}\left|\frac{1}{\left(\begin{array}{c}
n+j \\
j
\end{array}\right)} \sum_{k=0}^{j}\left(\begin{array}{c}
n+j-k-1 \\
j-k
\end{array}\right) u_{k}\right|
$$

respectively.

Theorem 3.3 Define the sequence $\left(b^{(k)}\right)=\left(b_{j}^{(k)}\right)$ for each $k \in \mathbb{N}$ by

$$
\left(b^{(k)}\right)_{j}=\left\{\begin{array}{ll}
(-1)^{j-k}\left(\begin{array}{c}
n-m \\
j-k
\end{array}\right)\left(\begin{array}{c}
n+k \\
k
\end{array}\right), & j \geq k, \\
0, & j<k,
\end{array} \quad\left(j \in \mathbb{N}_{0}\right) .\right.
$$

Then the sequence $\left(b^{(k)}\right)$ is a basis for the space $\ell_{p}\left(\Phi^{n, m}\right)$, and each $u \in \ell_{p}\left(\Phi^{n, m}\right)$ has a unique representation of the form $u=\sum_{k}\left(\Phi^{n, m} u\right)_{k} b^{(k)}$.

Proof Let $A$ be a triangle. By Theorem 2.3 of Jarrah and Malkowsky [28], the matrix domain $U_{A}$ has a basis if and only if the normed sequence space $U$ has a basis. Hence the proof follows immediately.

We use the following lemma to compute the dual spaces. By $\mathcal{N}$, we denote the family of all finite subsets of $\mathbb{N}$.

Lemma 3.4 ([29]) The following statements hold:

(i) $A=\left(a_{j k}\right) \in\left(\ell_{1}, \ell_{1}\right)$ if and only if

$$
\sup _{k} \sum_{j=0}^{\infty}\left|a_{j k}\right|<\infty
$$


(ii) $A=\left(a_{j k}\right) \in\left(\ell_{p}, \ell_{1}\right)$ if and only if

$$
\sum_{k=0}^{\infty}\left(\sum_{j=0}^{\infty}\left|a_{j k}\right|\right)^{p *}<\infty
$$

where $1<p<\infty$.

(iii) $A=\left(a_{j k}\right) \in\left(\ell_{\infty}, \ell_{1}\right)$ if and only if

$$
\sup _{K \in \mathcal{N}} \sum_{j=0}^{\infty}\left|\sum_{k \in K} a_{j k}\right|<\infty
$$

(iv) $A=\left(a_{j k}\right) \in\left(\ell_{1}, c\right)$ if and only if

$$
\lim _{j \rightarrow \infty} a_{j k} \text { exists for each } k \in \mathbb{N}
$$

and

$$
\sup _{j k}\left|a_{j k}\right|<\infty
$$

(v) $A=\left(a_{j k}\right) \in\left(\ell_{p}, c\right)$ if and only if (3.1) holds and

$$
\sup _{j} \sum_{k=0}^{\infty}\left|a_{j k}\right|^{p *}<\infty
$$

where $1<p<\infty$.

(vi) $A=\left(a_{j k}\right) \in\left(\ell_{\infty}, c\right)$ if and only if (3.1) holds and

$$
\lim _{j \rightarrow \infty} \sum_{k=0}^{\infty}\left|a_{j k}\right|=\sum_{k=0}^{\infty}\left|\lim _{j \rightarrow \infty} a_{j k}\right|
$$

(vii) $A=\left(a_{j k}\right) \in\left(\ell_{1}, \ell_{\infty}\right)$ if and only if (3.2) holds.

(viii) $A=\left(a_{j k}\right) \in\left(\ell_{p}, \ell_{\infty}\right)$ if and only if (3.3) holds, where $1<p<\infty$.

(ix) $A=\left(a_{j k}\right) \in\left(\ell_{\infty}, \ell_{\infty}\right)$ if and only if

$$
\sup _{j} \sum_{k=0}^{\infty}\left|a_{j k}\right|<\infty
$$

Dual spaces. The $\alpha$-dual of a sequence space $U$ consists of all sequences $a=\left(a_{k}\right) \in \omega$ such that $a u=\left(a_{k} u_{k}\right) \in \ell_{1}$ for all $u=\left(u_{k}\right) \in U$.

Theorem 3.5 The $\alpha$-duals of the spaces $\ell_{1}\left(\Phi^{n, m}\right), \ell_{p}\left(\Phi^{n, m}\right)(1<p<\infty)$ and $\ell_{\infty}\left(\Phi^{n, m}\right)$ are as follows:

$$
\left[\ell_{1}\left(\Phi^{n, m}\right)\right]^{\alpha}:=\left\{a=\left(a_{j}\right) \in \omega: \sup _{k} \sum_{j=0}^{\infty}\left|(-1)^{j-k}\left(\begin{array}{c}
n-m \\
j-k
\end{array}\right)\left(\begin{array}{c}
n+k \\
k
\end{array}\right) a_{j}\right|<\infty\right\},
$$




$$
\left[\ell_{p}\left(\Phi^{n, m}\right)\right]^{\alpha}:=\left\{a=\left(a_{j}\right) \in \omega: \sum_{k=0}^{\infty}\left(\sum_{j=0}^{\infty}\left|(-1)^{j-k}\left(\begin{array}{c}
n-m \\
j-k
\end{array}\right)\left(\begin{array}{c}
n+k \\
k
\end{array}\right) a_{j}\right|\right)^{p *}<\infty\right\}
$$

and

$$
\left[\ell_{\infty}\left(\Phi^{n, m}\right)\right]^{\alpha}:=\left\{a=\left(a_{j}\right) \in \omega: \sup _{K \in \mathcal{N}} \sum_{j=0}^{\infty}\left|\sum_{k \in K}(-1)^{j-k}\left(\begin{array}{c}
n-m \\
j-k
\end{array}\right)\left(\begin{array}{c}
n+k \\
k
\end{array}\right) a_{j}\right|<\infty\right\} .
$$

Proof Let $a=\left(a_{j}\right) \in \omega$ and define the matrix $D=\left(d_{j k}\right)$ as

$$
d_{j k}= \begin{cases}(-1)^{j-k}\left(\begin{array}{c}
n-m \\
j-k
\end{array}\right)\left(\begin{array}{c}
n+k \\
k
\end{array}\right) a_{j}, & 0 \leq k \leq j \\
0, & \text { otherwise }\end{cases}
$$

For any $u=\left(u_{j}\right) \in \ell_{p}\left(\Phi^{n, m}\right)(1<p<\infty)$, we have $a_{j} u_{j}=(D v)_{j}$ for all $j \in \mathbb{N}$. Thus $a u \in \ell_{1}$ with $u \in \ell_{p}\left(\Phi^{n, m}\right)$ if and only if $D v \in \ell_{1}$ with $v \in \ell_{p}$. Hence, we conclude that $a \in\left[\ell_{p}\left(\Phi^{n, m}\right)\right]^{\alpha}$ if and only if $D \in\left(\ell_{p}, \ell_{1}\right)$. This completes the proof by part (ii) of Lemma 3.4. The other cases can be proved similarly.

The $\beta$-dual of a sequence space $U$ consists of all sequences $a=\left(a_{k}\right) \in \omega$ such that $\left(\sum_{k=1}^{n} a_{k} u_{k}\right) \in c$ for all $u=\left(u_{k}\right) \in U$.

Theorem 3.6 Let us define the following sets:

$$
\begin{aligned}
& P_{1}:=\left\{a=\left(a_{k}\right) \in \omega: \lim _{j \rightarrow \infty} \sum_{i=k}^{j}(-1)^{i-k}\left(\begin{array}{c}
n-m \\
i-k
\end{array}\right)\left(\begin{array}{c}
n+k \\
k
\end{array}\right) a_{i} \text { exists for each } k \in \mathbb{N}\right\}, \\
& P_{2}:=\left\{a=\left(a_{k}\right) \in \omega: \sup _{j k}\left|\sum_{i=k}^{j}(-1)^{i-k}\left(\begin{array}{c}
n-m \\
i-k
\end{array}\right)\left(\begin{array}{c}
n+k \\
k
\end{array}\right) a_{i}\right|<\infty\right\}, \\
& P_{3}:=\left\{a=\left(a_{k}\right) \in \omega: \sup _{j} \sum_{k=0}^{\infty}\left|\sum_{i=k}^{j}(-1)^{i-k}\left(\begin{array}{c}
n-m \\
i-k
\end{array}\right)\left(\begin{array}{c}
n+k \\
k
\end{array}\right) a_{i}\right|^{p *}<\infty\right\},
\end{aligned}
$$

and

$$
\begin{aligned}
P_{4}:= & \left\{a=\left(a_{k}\right) \in \omega:\right. \\
& \left.\lim _{j \rightarrow \infty} \sum_{k=0}^{\infty}\left|\sum_{i=k}^{j}(-1)^{i-k}\left(\begin{array}{c}
n-m \\
i-k
\end{array}\right)\left(\begin{array}{c}
n+k \\
k
\end{array}\right) a_{i}\right|=\sum_{k=0}^{\infty}\left|\sum_{i=k}^{\infty}(-1)^{i-k}\left(\begin{array}{c}
n-m \\
i-k
\end{array}\right)\left(\begin{array}{c}
n+k \\
k
\end{array}\right) a_{i}\right|\right\} .
\end{aligned}
$$

Then $\left[\ell_{1}\left(\Phi^{n, m}\right)\right]^{\beta}=P_{1} \cap P_{2},\left[\ell_{p}\left(\Phi^{n, m}\right)\right]^{\beta}=P_{1} \cap P_{3}(1<p<\infty)$ and $\left[\ell_{\infty}\left(\Phi^{n, m}\right)\right]^{\beta}=P_{1} \cap P_{4}$ hold.

Proof $a=\left(a_{k}\right) \in\left[\ell_{1}\left(\Phi^{n, m}\right)\right]^{\beta}$ if and only if the series $\sum_{k=0}^{\infty} a_{k} u_{k}$ is convergent for all $u=$ $\left(u_{k}\right) \in \ell_{1}\left(\Phi^{n, m}\right)$. From the equality

$$
\sum_{k=0}^{j} a_{k} u_{k}=\sum_{k=0}^{j} a_{k}\left(\sum_{i=0}^{k}(-1)^{k-i}\left(\begin{array}{c}
n-m \\
k-i
\end{array}\right)\left(\begin{array}{c}
n+i \\
i
\end{array}\right) v_{i}\right)
$$




$$
=\sum_{k=0}^{j}\left(\sum_{i=k}^{j}(-1)^{i-k}\left(\begin{array}{c}
n-m \\
i-k
\end{array}\right)\left(\begin{array}{c}
n+k \\
k
\end{array}\right) a_{i}\right) v_{k}
$$

it follows that $a=\left(a_{k}\right) \in\left[\ell_{1}\left(\Phi^{n, m}\right)\right]^{\beta}$ if and only if the matrix $P=\left(p_{j k}\right)$ is in $\left(\ell_{1}, c\right)$, where

$$
p_{j k}= \begin{cases}\sum_{i=k}^{j}(-1)^{i-k}\left(\begin{array}{c}
n-m \\
i-k
\end{array}\right)\left(\begin{array}{c}
n+k \\
k
\end{array}\right) a_{i}, & 0 \leq k \leq j \\
0, & \text { otherwise }\end{cases}
$$

Hence, by part (iv) of Lemma 3.4 we conclude that

$$
\lim _{j \rightarrow \infty} \sum_{i=k}^{n}(-1)^{i-k}\left(\begin{array}{c}
n-m \\
i-k
\end{array}\right)\left(\begin{array}{c}
n+k \\
k
\end{array}\right) a_{i} \text { exists for each } k \in \mathbb{N}
$$

and

$$
\sup _{j k}\left|\sum_{i=k}^{j}(-1)^{i-k}\left(\begin{array}{c}
n-m \\
i-k
\end{array}\right)\left(\begin{array}{c}
n+k \\
k
\end{array}\right) a_{i}\right|<\infty
$$

which means $a=\left(a_{k}\right) \in P_{1} \cap P_{2}$ and so we have $\left[\ell_{1}\left(\Phi^{n, m}\right)\right]^{\beta}=P_{1} \cap P_{2}$. The other cases can be proved similarly.

The $\gamma$-dual of a sequence space $U$ consists of all sequences $a=\left(a_{k}\right) \in \omega$ such that $\left(\sum_{k=1}^{n} a_{k} u_{k}\right) \in \ell_{\infty}$ for all $u=\left(u_{k}\right) \in U$.

Theorem 3.7 The $\gamma$-duals of the spaces $\ell_{1}\left(\Phi^{n, m}\right), \ell_{p}\left(\Phi^{n, m}\right)(1<p<\infty)$ and $\ell_{\infty}\left(\Phi^{n, m}\right)$ are as follows:

$$
\begin{aligned}
& {\left[\ell_{1}\left(\Phi^{n, m}\right)\right]^{\gamma}:=\left\{a=\left(a_{k}\right) \in \omega: \sup _{j k}\left|\sum_{i=k}^{j}(-1)^{i-k}\left(\begin{array}{c}
n-m \\
i-k
\end{array}\right)\left(\begin{array}{c}
n+k \\
k
\end{array}\right) a_{i}\right|<\infty\right\},} \\
& {\left[\ell_{p}\left(\Phi^{n, m}\right)\right]^{\gamma}:=\left\{a=\left(a_{k}\right) \in \omega: \sup _{j} \sum_{k=0}^{\infty}\left|\sum_{i=k}^{j}(-1)^{i-k}\left(\begin{array}{c}
n-m \\
i-k
\end{array}\right)\left(\begin{array}{c}
n+k \\
k
\end{array}\right) a_{i}\right|^{p *}<\infty\right\},}
\end{aligned}
$$

and

$$
\left[\ell_{\infty}\left(\Phi^{n, m}\right)\right]^{\gamma}:=\left\{a=\left(a_{k}\right) \in \omega: \sup _{j} \sum_{k=0}^{\infty}\left|\sum_{i=k}^{j}(-1)^{i-k}\left(\begin{array}{c}
n-m \\
i-k
\end{array}\right)\left(\begin{array}{c}
n+k \\
k
\end{array}\right) a_{i}\right|<\infty\right\} .
$$

Proof By using the same technique as in the proof of Theorem 3.6, we obtain the gamma duals.

\subsection{Fractional difference spaces}

The sequence spaces $\ell_{p}\left(\Psi^{n, m}\right)(1<p<\infty)$ and $\ell_{\infty}\left(\Psi^{n, m}\right)$ are introduced similarly by

$$
\ell_{p}\left(\Psi^{n, m}\right)=\left\{u=\left(u_{j}\right) \in \omega: \sum_{j=0}^{\infty}\left|\frac{1}{\left(\begin{array}{c}
n+j \\
j
\end{array}\right)} \sum_{k=0}^{j}(-1)^{j-k}\left(\begin{array}{c}
m-n \\
j-k
\end{array}\right) u_{k}\right|^{p}<\infty\right\}
$$


and

$$
\ell_{\infty}\left(\Psi^{n, m}\right)=\left\{u=\left(u_{j}\right) \in \omega: \sup _{j}\left|\frac{1}{\left(\begin{array}{c}
n+j \\
j
\end{array}\right)} \sum_{k=0}^{j}(-1)^{j-k}\left(\begin{array}{c}
m-n \\
j-k
\end{array}\right) u_{k}\right|<\infty\right\} .
$$

Theorem 3.8 The spaces $\ell_{p}\left(\Psi^{n, m}\right)$ and $\ell_{\infty}\left(\Psi^{n, m}\right)$ are Banach spaces with the norms

$$
\|u\|_{\ell_{p}\left(\Psi^{n, m}\right)}=\left(\sum_{j=0}^{\infty}\left|\frac{1}{\left(\begin{array}{c}
n+j \\
j
\end{array}\right)} \sum_{k=0}^{j}(-1)^{j-k}\left(\begin{array}{c}
m-n \\
j-k
\end{array}\right) u_{k}\right|^{p}\right)^{1 / p}
$$

and

$$
\|u\|_{\ell_{\infty}\left(\Psi^{n, m}\right)}=\sup _{j}\left|\frac{1}{\left(\begin{array}{c}
n+j \\
j
\end{array}\right)} \sum_{k=0}^{j}(-1)^{j-k}\left(\begin{array}{c}
m-n \\
j-k
\end{array}\right) u_{k}\right|
$$

respectively.

Proof We omit the proof, which is a routine verification.

Theorem 3.9 Define the sequence $\left(d^{(k)}\right)=\left(d_{j}^{(k)}\right)$ for each $k \in \mathbb{N}$ by

$$
\left(d^{(k)}\right)_{j}=\left\{\begin{array}{ll}
\left(\begin{array}{c}
m-n+j-k-1 \\
j-k
\end{array}\right)\left(\begin{array}{c}
n+k \\
k
\end{array}\right), & j \geq k, \\
0, & j<k,
\end{array} \quad\left(j \in \mathbb{N}_{0}\right)\right.
$$

Then the sequence $\left(d^{(k)}\right)$ is a basis for the space $\ell_{p}\left(\Psi^{n, m}\right)$, and each $u \in \ell_{p}\left(\Psi^{n, m}\right)$ has a unique representation of the form $u=\sum_{k}\left(\Psi^{n, m} u\right)_{k} d^{(k)}$.

Theorem 3.10 The $\alpha$-duals of the spaces $\ell_{1}\left(\Psi^{n, m}\right), \ell_{p}\left(\Psi^{n, m}\right)(1<p<\infty)$ and $\ell_{\infty}\left(\Psi^{n, m}\right)$ are as follows:

$$
\begin{aligned}
& {\left[\ell_{1}\left(\Psi^{n, m}\right)\right]^{\alpha}:=\left\{a=\left(a_{j}\right) \in \omega: \sup _{k} \sum_{j=0}^{\infty}\left|\left(\begin{array}{c}
m-n+j-k-1 \\
j-k
\end{array}\right)\left(\begin{array}{c}
n+k \\
k
\end{array}\right) a_{j}\right|<\infty\right\},} \\
& {\left[\ell_{p}\left(\Psi^{n, m}\right)\right]^{\alpha}:=\left\{a=\left(a_{j}\right) \in \omega: \sum_{k=0}^{\infty}\left(\sum_{j=0}^{\infty}\left|\left(\begin{array}{c}
m-n+j-k-1 \\
j-k
\end{array}\right)\left(\begin{array}{c}
n+k \\
k
\end{array}\right) a_{j}\right|\right)^{p *}<\infty\right\},}
\end{aligned}
$$

and

$$
\left[\ell_{\infty}\left(\Psi^{n, m}\right)\right]^{\alpha}:=\left\{a=\left(a_{j}\right) \in \omega: \sup _{K \in \mathcal{N}} \sum_{j=0}^{\infty}\left|\sum_{k \in K}\left(\begin{array}{c}
m-n+j-k-1 \\
j-k
\end{array}\right)\left(\begin{array}{c}
n+k \\
k
\end{array}\right) a_{j}\right|<\infty\right\} .
$$

Proof The proof is similar to the proof of Theorem 3.5.

Theorem 3.11 Let us define the following sets:

$$
Q_{1}:=\left\{a=\left(a_{k}\right) \in \omega: \lim _{j \rightarrow \infty} \sum_{i=k}^{j}\left(\begin{array}{c}
m-n+i-k-1 \\
i-k
\end{array}\right)\left(\begin{array}{c}
n+k \\
k
\end{array}\right) a_{i} \text { exists for each } k \in \mathbb{N}\right\}
$$




$$
\begin{aligned}
& Q_{2}:=\left\{a=\left(a_{k}\right) \in \omega: \sup _{j k}\left|\sum_{i=k}^{j}\left(\begin{array}{c}
m-n+i-k-1 \\
i-k
\end{array}\right)\left(\begin{array}{c}
n+k \\
k
\end{array}\right) a_{i}\right|<\infty\right\}, \\
& Q_{3}:=\left\{a=\left(a_{k}\right) \in \omega: \sup _{j} \sum_{k=0}^{\infty}\left|\sum_{i=k}^{j}\left(\begin{array}{c}
m-n+i-k-1 \\
i-k
\end{array}\right)\left(\begin{array}{c}
n+k \\
k
\end{array}\right) a_{i}\right|^{p *}<\infty\right\},
\end{aligned}
$$

and

$$
\begin{aligned}
& Q_{4}:=\{a=\left(a_{k}\right) \in \omega: \\
& \lim _{j \rightarrow \infty} \sum_{k=0}^{\infty}\left|\sum_{i=k}^{j}\left(\begin{array}{c}
m-n+i-k-1 \\
i-k
\end{array}\right)\left(\begin{array}{c}
n+k \\
k
\end{array}\right) a_{i}\right| \\
&\left.\quad=\sum_{k=0}^{\infty}\left|\sum_{i=k}^{\infty}\left(\begin{array}{c}
m-n+i-k-1 \\
i-k
\end{array}\right)\left(\begin{array}{c}
n+k \\
k
\end{array}\right) a_{i}\right|\right\} .
\end{aligned}
$$

Then $\left[\ell_{1}\left(\Psi^{n, m}\right)\right]^{\beta}=Q_{1} \cap Q_{2},\left[\ell_{p}\left(\Psi^{n, m}\right)\right]^{\beta}=Q_{1} \cap Q_{3}(1<p<\infty)$ and $\left[\ell_{\infty}\left(\Psi^{n, m}\right)\right]^{\beta}=Q_{1} \cap Q_{4}$ hold.

Proof The proof is similar to the proof of Theorem 3.6.

Theorem 3.12 The $\gamma$-duals of the spaces $\ell_{1}\left(\Psi^{n, m}\right), \ell_{p}\left(\Psi^{n, m}\right)(1<p<\infty)$ and $\ell_{\infty}\left(\Psi^{n, m}\right)$ are as follows:

$$
\begin{aligned}
& {\left[\ell_{1}\left(\Psi^{n, m}\right)\right]^{\gamma}:=\left\{a=\left(a_{k}\right) \in \omega: \sup _{j k}\left|\sum_{i=k}^{j}\left(\begin{array}{c}
m-n+i-k-1 \\
i-k
\end{array}\right)\left(\begin{array}{c}
n+k \\
k
\end{array}\right) a_{i}\right|<\infty\right\},} \\
& {\left[\ell_{p}\left(\Psi^{n, m}\right)\right]^{\gamma}:=\left\{a=\left(a_{k}\right) \in \omega: \sup _{j} \sum_{k=0}^{\infty}\left|\sum_{i=k}^{j}\left(\begin{array}{c}
m-n+i-k-1 \\
i-k
\end{array}\right)\left(\begin{array}{c}
n+k \\
k
\end{array}\right) a_{i}\right|^{p *}<\infty\right\},}
\end{aligned}
$$

and

$$
\left[\ell_{\infty}\left(\Psi^{n, m}\right)\right]^{\gamma}:=\left\{a=\left(a_{k}\right) \in \omega: \sup _{j} \sum_{k=0}^{\infty}\left|\sum_{i=k}^{j}\left(\begin{array}{c}
m-n+i-k-1 \\
i-k
\end{array}\right)\left(\begin{array}{c}
n+k \\
k
\end{array}\right) a_{i}\right|<\infty\right\} .
$$

Proof The proof is similar to the proof of Theorem 3.7.

Funding

There is no fund for this paper.

\section{Availability of data and materials}

Data sharing not applicable to this article as no datasets were generated or analyzed during the current study.

\section{Competing interests}

The authors declare that they have no competing interests.

Authors' contributions

The authors played the same role in writing this paper. All authors read and approved the final manuscript.

\section{Author details}

'Department of Mathematics, University of Alberta, Edmonton, Canada. ${ }^{2}$ Department of Mathematics, Gauhati

University, Assam, India. 


\section{Publisher's Note}

Springer Nature remains neutral with regard to jurisdictional claims in published maps and institutional affiliations.

Received: 21 March 2021 Accepted: 23 June 2021 Published online: 09 July 2021

\section{References}

1. Başar, F., Kiriş̧̧i, M.: Almost convergence and generalized difference matrix. Comput. Math. Appl. 61(3), 602-611 (2011)

2. Başarır, M., Kara, E.E.: On the B-difference sequence space derived by generalized weighted mean and compact operators. J. Math. Anal. Appl. 391, 67-81 (2012)

3. Bektaş, Ç.A., Et, M., Çolak, R.: Generalized difference sequence spaces and their dual spaces. J. Math. Anal. Appl. 292(2), 423-432 (2004)

4. IIlkhan, M., Kara, E.E.: A new Banach space defined by Euler totient matrix operator. Oper. Matrices 13(2), 527-544 (2019)

5. Illkhan, M., Roopaei, H.: The Cesàro-Gamma operator and its associated sequence space. Adv. Oper. Theory 45(6) (2021)

6. Roopaei, H. Illkhan, M.: Fractional Cesàro matrix and its associated sequence space. Concr. Oper. 8(1), 24-39 (2021)

7. Roopaei, H., Foroutannia, D., Ilkhan, M., Kara, E.E.: Cesàro spaces and norm of operators on these matrix domains. Mediterr. J. Math. 17, 121 (2020)

8. Roopaei, H., Başar, F.: On the spaces of Cesàro absolutely $p$-summable, null, and convergent sequences. Math Methods Appl. Sci. 44(5), 3670-3685 (2021)

9. Roopaei, H.: A study on Copson operator and its associated sequence spaces. J. Inequal. Appl. 2020, 120 (2020)

10. Roopaei, H.: A study on Copson operator and its associated sequence spaces II. J. Inequal. Appl. 2020, 239 (2020)

11. Roopaei, H., Mursaleen, M.: Sequence spaces associated with fractional Copson matrix and compact operators. Results Math. 76, 134 (2021)

12. Kama, R., Altay, B., Başar, F:: On the domains of backward difference matrix and the spaces of convergence of a series. Bull. Allahabad Math. Soc. 33(1), 139-153 (2018)

13. Altay, B., Kama, R.: On Cesàro summability of vector valued multiplier spaces and operator valued series. Positivity 22(2), 575-586 (2018)

14. Kama, R.: On some vector valued multiplier spaces with statistical Cesàro summability. Filomat 33(16), 5135-5147 (2019)

15. Ercan, S., Bektas, Ç.A.: On new convergent difference BK-spaces. J. Comput. Anal. Appl. 23(5), 793-801 (2017)

16. Ercan, S.: On deferred Cesàro mean in the paranormed spaces. Korean J. Math. 29(1), 169-177 (2021)

17. Başar, F:: Summability Theory and Its Applications. Bentham Science Publishers, e-books, monograph, ístanbul (2012)

18. Mursaleen, M.: Applied Summability Methods. Springer Briefs (2014)

19. Hardy, G.H.: Divergent Series. Oxford University Press, London (1973) Cambridge, 2001

20. Ng, P.-N., Lee, P.-Y.: Cesàro sequence spaces of non-absolute type. Comment. Math. Prace Mat. 20(2), 429-433 (1978)

21. Başar, F., Altay, B.: On the space of sequences of p-bounded variation and related matrix mappings. Ukr. Math. J. 55(1), 136-147 (2003)

22. Altay, B., Başar, F.: The matrix domain and the fine spectrum of the difference operator $\Delta$ on the sequence space $\ell_{p}$, $(0<p<1)$. Commun. Math. Anal. 2(2), 1-11 (2007)

23. Çolak, R., Et, M., Malkowsky, E.: Some Topics of Sequence Spaces. Lecture Notes in Mathematics, Firat Univ. Elâzig, Turkey, 2004, Firat Univ. Press pp. 1-63 (2004) ISBN: 975-394-038-6

24. Altay, B:: On the space of $p$-summable difference sequences of order $m,(1 \leq p<\infty)$. Studia Sci. Math. Hung. 43(4), 387-402 (2006)

25. Malkowsky, E., Parashar, S.D.: Matrix transformations in space of bounded and convergent difference sequences of order $m$. Analysis 17, 87-97 (1997)

26. Et, M.: On some generalized Cesàro difference sequence spaces. Istanb. Üniv. Fen Fak. Mat. Derg. 55-56, 221-229 (1996-1997)

27. Bennett, G.: Factorizing the classical inequalities. Mem. Am. Math. Soc. 576 (1996)

28. Jarrah, A.M., Malkowsky, E.: BK spaces, bases and linear operators. Rend. Circ. Mat. Palermo (2) Suppl. 52, 177-191 (1990)

29. Stieglitz, M., Tietz, H.: Matrix transformationen von folgenraumen eine Ergebnisübersicht. Math. Z. 154, 116 (1977)

\section{Submit your manuscript to a SpringerOpen ${ }^{\circ}$ journal and benefit from:}

- Convenient online submission

- Rigorous peer review

- Open access: articles freely available online

- High visibility within the field

- Retaining the copyright to your article

Submit your next manuscript at $\gg$ springeropen.com 